\title{
Chloroquine reduces arylsulphatase $B$ activity and increases chondroitin-4-sulphate: implications for mechanisms of action and resistance
}

\author{
Sumit Bhattacharyya ${ }^{1,2}$, Kemal Solakyildirim³ ${ }^{3}$ Zhenqing Zhang3, \\ Robert J Linhardt ${ }^{3}$ and Joanne K Tobacman*1,2
}

Address: ${ }^{1}$ Department of Medicine, University of Illinois at Chicago, 840 S. Wood St., CSN 440 M/C 718 Chicago, IL 60612, USA, ${ }^{2}$ Jesse Brown VA Medical Center, Chicago, IL, USA and ${ }^{3}$ Department of Chemistry and Chemical Biology, Rensselaer Polytechnic Institute, Troy, NY, USA

Email: Sumit Bhattacharyya - ramabha@uic.edu; Kemal Solakyildirim - solakk@rpi.edu; Zhenqing Zhang - zhangz5@rpi.edu; Robert J Linhardt - linhar@rpi.edu; Joanne K Tobacman* - jkt@uic.edu

* Corresponding author

Published: 17 December 2009

Malaria Journal 2009, 8:303 doi:10.1 I86/1475-2875-8-303
Received: 7 August 2009

Accepted: 17 December 2009

This article is available from: http://www.malariajournal.com/content/8/I/303

(c) 2009 Bhattacharyya et al; licensee BioMed Central Ltd.

This is an Open Access article distributed under the terms of the Creative Commons Attribution License (http://creativecommons.org/licenses/by/2.0), which permits unrestricted use, distribution, and reproduction in any medium, provided the original work is properly cited.

\begin{abstract}
Background: The receptors for adhesion of Plasmodium falciparum-infected red blood cells (RBC) in the placenta have been identified as chondroitin-4-sulphate (C4S) proteoglycans, and the more sulphate-rich chondroitin oligosaccharides have been reported to inhibit adhesion. Since the antimalarial drug chloroquine accumulates in lysosomes and alters normal lysosomal processes, the effects of chloroquine on the lysosomal enzyme arylsulphatase B (ASB, N-acetylgalactosamine-4sulphatase), which removes 4-sulphate groups from chondroitin-4-sulphate, were addressed. The underlying hypothesis derived from the recognized impairment of attachment of parasite-infected erythrocytes in the placenta, when chondroitin-4-sulphation was increased. If chloroquine reduced ASB activity, leading to increased chondroitin-4-sulphation, it was hypothesized that the antimalarial mechanism of chloroquine might derive, at least in part, from suppression of ASB.

Methods: Experimental methods involved cell culture of human placental, bronchial epithelial, and cerebrovascular cells, and the in vitro exposure of the cells to chloroquine at increasing concentrations and durations. Measurements of arylsulphatase $B$ enzymatic activity, total sulphated glycosaminoglycans (sGAG), and chondroitin-4-sulphate (C4S) were performed using in vitro assays, following exposure to chloroquine and in untreated cell preparations. Fluorescent immunostaining of ASB was performed to determine the effect of chloroquine on cellular ASB content and localization. Mass spectrometry and high performance liquid chromatography were performed to document and to quantify the changes in chondroitin disaccharides following chloroquine exposure.
\end{abstract}

Results: In the human placental, bronchial epithelial, and cerebrovascular cells, exposure to increasing concentrations of chloroquine was associated with reduced ASB activity and with increased concentrations of SGAG, largely attributable to increased C4S. The study data demonstrated: I) decline in ASB activity following chloroquine exposure; 2) inverse correlation between ASB activity and C4S content; 3) increased content of chondroitin-4-sulphate disaccharides following chloroquine exposure; and 4) decline in extent of chloroquine-induced ASB 
reduction with lower baseline ASB activity. Confocal microscopy demonstrated the presence of ASB along the cell periphery, indicating extra-lysosomal localization.

Conclusions: The study data indicate that the therapeutic mechanism of chloroquine action may be attributable, at least in part, to reduction of ASB activity, leading to increased chondroitin-4sulphation in human placental, bronchial epithelial, and cerebrovascular cells. In vivo, increased chondroitin-4-sulphation may reduce the attachment of $P$. falciparum-infected erythrocytes to human cells. Extra-lysosomal localization of ASB and reduced impact of chloroquine when baseline ASB activity is less suggest possible mechanisms of resistance to the effects of chloroquine.

\section{Background}

The presence of the sulphated glycosaminoglycan (sGAG), chondroitin-4-sulphate (C4S) has been demonstrated to affect the adherence of Plasmodium falciparuminfected erythrocytes to endothelial cells of the vasculature in models of malaria [1-6]. Attachment of the P. falciparum-infected erythrocytes was greater when sulphation of chondroitin-4-sulphate (C4S) was less, and increased sulphation of $\mathrm{C} 4 \mathrm{~S}$ reduced attachment of infected erythrocytes. Also, severity of malarial infection has been associated with the extent of sulphation of chondroitin-4sulphate of the intervillous cells of the placenta in models of maternal-fetal transmission of malaria [7-12]. Since the accumulation of infected erythrocytes induces the capillary damage and organ dysfunction pathognomonic of malaria, consideration of the possible role of the enzyme arylsulphatase B (ASB; N-acetylgalactosamine-4-sulphatase), which hydrolyzes the 4-sulphate group of $\mathrm{C} 4 \mathrm{~S}$, was of interest.

In humans, the enzyme ASB has been regarded as solely a lysosomal enzyme, since inborn deficiency of ASB causes the lysosomal storage disease Mucopolysaccharidosis VI (MPS VI), also known as Maroteaux-Lamy syndrome. In MPS VI, the accumulation of sulphated glycosaminoglycans, including $\mathrm{C} 4 \mathrm{~S}$ and dermatan sulphate, produces severe organ dysfunction and premature death. Significant effects of the enzyme ASB on the content of C4S in human colonic, bronchial, and mammary epithelial cells in tissue culture [13-16] were reported recently. These reports demonstrated extra-lysosomal localization of ASB in human colonic and bronchial epithelial cell, as well as other significant biological effects of ASB, affecting cell signaling, cell migration, and inflammation [13-17].

Since ASB activity affects the sulphation of C4S and sulphation of C4S affects the attachment of $P$. falciparuminfected red blood cells, modifications of ASB activity might influence malarial infectivity. If the lysosomotropic anti-malarial drug chloroquine could affect the activity of the enzyme ASB, this might influence disease activity and might explain, at least to some extent, the anti-malarial effect of chloroquine. In this report, evidence of the effect of chloroquine on ASB activity and C4S content in human placental, bronchial epithelial, and cerebrovascular cells in tissue culture is presented.

\section{Methods \\ Cells and cell culture}

Human placental fibroblastic (ATCC; Manassas, VA, USA), bronchial epithelial (C38 and IB3-1; ATCC), primary bronchial epithelial (BEC; Clonetics ${ }^{\circledR}$ NHBE, Lonza, Walkersville, MD, USA), and primary cerebrovascular cells [CVC; ScienCellTM HBMEC (human brain microvascular endothelial cells), Carlsbad, CA] were obtained and grown according to recommendations and as previously reported [13-15]. IB3-1 and C38 cells were grown in $75 \mathrm{ml}$ flasks coated with human fibronectin $(10 \mu \mathrm{g} / \mathrm{ml}$, SigmaAldrich, St. Louis, MO), vitrogen (30 $\mu \mathrm{g} / \mathrm{ml}$, Cohesion), and bovine serum albumin $(10 \mu \mathrm{g} / \mathrm{ml})$, using LHC-8 medium without phenol red (Invitrogen, Carlsbad, CA), containing $0.5 \mathrm{ng} / \mathrm{ml}$ recombinant epidermal growth factor, $6 \mathrm{mM}$ glutamine, $0.005 \mathrm{mg} / \mathrm{ml}$ insulin, $500 \mathrm{ng} / \mathrm{ml}$ hydrocortisone, $0.035 \mathrm{mg} / \mathrm{ml}$ bovine pituitary extract, and $50 \mu \mathrm{g} / \mathrm{ml}$ gentamicin. Primary bronchial epithelial cells (BEC) were grown in BEGM ${ }^{\circledast}$ (Clonetics). Cerebrovascular cells were grown in ECM (ScienCell), and placental cells were grown in DMEM with 10\% FBS. All cells were grown in a $5 \% \mathrm{CO} 2$ environment at $37^{\circ} \mathrm{C}$ and $95 \%$ humidity. Cells reached $80 \%$ confluence in about one week and were harvested by scraping, or by recommended EDTA-trypsin subculture reagent. Cell preparations were processed for measurements of ASB activity, ASB protein and mRNA expression, cell protein, sGAG, and C4S in control samples and following treatment with chloroquine (Sigma Chemical Company, St. Louis, MO) for 24 hours at a concentration of $50 \mathrm{nM}$, unless stated otherwise. CVC cells stained positively for CD31 using a standard protocol [Santa Cruz Biotechnology (SCBT), Santa Cruz, CA].

\section{Measurement of ASB activity}

ASB measurements were by a fluorometric assay using the synthetic substrate 4-methylumbilliferyl sulphate (4MUS), following a standard protocol [13-17]. Protein content of the cell homogenate was measured using $\mathrm{BCA}^{\mathrm{TM}}$ Protein Assay Kit (Pierce), and ASB activity was expressed as $\mathrm{nmol} / \mathrm{mg}$ cell protein/hr. ASB protein in the control 
and chloroquine-treated cells was measured by a FACEELISA (fast-activated cell-based ELISA; Active Motif, CA). Placental cells were grown in a 96-well plate and treated with chloroquine $50 \mathrm{nM} \times 24$ hours). Treated and control cells were washed and fixed with $4 \%$ formaldehyde in PBS. After 20 minutes, formaldehyde was aspirated, cells were washed with PBS, and treated with quenching buffer, to suppress endogenous peroxidase activity. Cells were treated with blocking buffer and incubated overnight at $4^{\circ} \mathrm{C}$ with polyclonal rabbit antibody to ASB (1:50; Open Biosystems, Huntsville, AL). Binding of primary antibodies to cells was detected by secondary goat anti-rabbit IgGHRP, and bound HRP activity was developed by hydrogen peroxide/TMB substrate. The reaction was stopped by $2 \mathrm{~N}$ sulfuric acid, and the optical density was measured in an ELISA plate reader (FLUOstar, BMG Labtech, Cary, NC) at $450 \mathrm{~nm}$. After the reading, cells were washed thoroughly and incubated in crystal violet solution for 30 minutes, followed by 1\% SDS (sodium dodecyl sulfate) solution for one hour. Colour was proportionate to the cell number which was measured by optical density using the ELISA plate reader at $592 \mathrm{~nm}$. This reading was used to normalize the first reading (per equal number of cells), and the result was expressed as \% of control for the ASB protein.

\section{Measurement of sulphated glycosaminoglycans}

Total sulphated glycosaminoglycan (sGAG) content, including chondroitin-4-sulphate (C4S), chondroitin-6sulphate (C6S), keratan sulphate, dermatan sulphate, heparan sulphate, and heparin, was measured in cell lysates by sulphated GAG assay (Blyscan ${ }^{\mathrm{TM}}$, Biocolor Ltd, Newtownabbey, Northern Ireland), using labeled 1,9dimethylmethylene blue, as previously reported [14-16]. Hyaluronan and degraded disaccharide fragments were not measured by this assay. The reaction was performed in the presence of excess unbound dye. The cationic dye and GAG at acid $\mathrm{pH}$ produced an insoluble dye-GAG complex, and the GAG content was determined by the amount of dye that was recovered from the test sample following exposure to Blyscan Dissociation Reagent. Absorbance maximum of 1,9-dimethylmethylene blue is $656 \mathrm{~nm}$. Concentration is expressed as $\mu \mathrm{g} / \mathrm{mg}$ protein of cell lysate. Dye-GAG complex is proportional $(1: 1)$ to the sulphate content for C4S.

\section{Immunoprecipitation of cell lysates by chondroitin-4- sulphate}

Cell lysates were prepared from chloroquine-treated and control cells. Chondroitin-4-sulphate (C4S; 4D1) antibody to native C4S was procured (SCBT). No prior enzymatic digestion of the cell samples by chondroitinase $\mathrm{ABC}$ was performed. Antibody was added to the cell lysates in tubes (C4S antibody at a concentration of $1 \mu \mathrm{g} / \mathrm{mg}$ protein; CS to a final dilution of 1:50), and the tubes were rotated overnight in a shaker at $4{ }^{\circ} \mathrm{C}$, as previously reported [14]. Next, $100 \mu \mathrm{l}$ of pre-washed Protein L-Agarose (Santa Cruz) was added to each tube, tubes were incubated overnight at $4^{\circ} \mathrm{C}$, and the Protein L-Agarose treated beads were washed three times with PBS containing Protease Inhibitor Cocktail. The precipitate was eluted with dye-free elution buffer and subjected to sulphated GAG assay.

\section{ASB Knockdown by siRNA}

Small interfering RNA (siRNA) to knockdown ASB (NM_000046) was obtained commercially (Qiagen, Valencia, CA) and tested for effective knockdown by Western blot and by ASB activity assay. siRNA for ASB (150 ng; $0.6 \mu \mathrm{l})$ in $100 \mu \mathrm{l}$ serum-free culture medium and $12 \mu \mathrm{l}$ of HiPerfect Transfection Reagent (Qiagen) were combined, as previously described [14-16]. For ASB silencing, the siRNA sequences were:

\section{Sense: 5'-GGGUAUGGUCUCUAGGCAtt-3'}

\section{Antisense: 5'-UUGCCUAGAGACCAUACCCtt-3'}

For the negative control, the siRNA sequences were:

\section{Sense: 5'-UUCUCCGAACGUGUCACGUtt-3'}

\section{Antisense: 5'-ACGUGACACGUUCGGAGAAtt-3'}

\section{Confocal microscopy}

For confocal microscopy, the BEC or CVC were grown in four-chamber tissue culture slides for 24 hours, as previously described [16]. Half of the wells were treated with chloroquine $50 \mathrm{nM}$ for 24 hours; cells were then fixed in $95 \%$ ethanol for $30 \mathrm{~min}$ and refrigerated. Slides were washed once in $1 \times$ PBS containing $1 \mathrm{mM}$ calcium chloride (pH 7.4) and permeabilized with $0.08 \%$ saponin. Preparations were washed with PBS, blocked with 5\% normal goat serum, and incubated overnight with ASB polyclonal antibody (Open Biosystems, ThermoFisher Scientific, Hunstville, AL) at $4^{\circ} \mathrm{C}$. Specificity of the ASB antibody was determined by inhibition of positive staining with the peptide that was the epitope for generation of the antibody. Slides were washed and stained with goat-anti-rabbit Alexa Fluor ${ }^{\circledR}$ IgG 568 (1:100, Invitrogen) and with Alexa Fluor ${ }^{\circledR}$ Phalloidin 488 (1:60, Invitrogen) to stain actin in the CVC cell preparations. Slides were washed thoroughly, and stained cells were observed with a Zeiss LSM 510 laser scanning confocal microscope (excitation $488 \mathrm{~nm}$ and $534 \mathrm{~nm}$ from an $\mathrm{Ar} / \mathrm{Kr}$ laser. Green (F-actin) and red (ASB) fluorescence were detected through LP505 and 585 filters. The fluorochromes were scanned sequentially, and the collected images were exported by Zeiss LSM Image Browser software as TIFF files for analysis and reproduction. 


\section{QPCR for ASB mRNA expression}

C38 and IB3-1 lung epithelial cells were grown in 12-well tissue culture plates and treated with chloroquine $50 \mu \mathrm{M}$ for 24 hours. At the end of the treatment, total RNA was isolated by RNeasy mini kit (Qiagen) from three control and three treated cell preparations. Three aliquots of equal amounts of RNA from each control or chloroquinetreated cell preparation were reverse transcribed and then amplified for 40 cycles, using Brilliant SYBR Green QRTPCR MasterMix kit (Stratagene) and Mx3000P QRT-PCR system (Stratagene). ASB mRNA expression in control and treated cells was determined by amplification with the following primers for ASB (NCBI NM_000046), that were designed using Primer 3 software:

\section{ASB forward: 5'AGACTTTGGCAGGGGGTAAT-3'}

\section{ASB reverse: 5'CAGCCAGTCAGAGATGTGGA-3'}

Human $\beta$-actin was used an internal control. Fold changes in ASB mRNA expression due to chloroquine treatment were determined from the differences between the cycle thresholds using the following formulae and CT values that were the mean of nine determinations:

Fold change $=2^{\Delta 3}$ with $\Delta 3=\Delta 1-\Delta 2$, where $\Delta 1=$ CT control ASB - CT control actin and $\Delta 2=$ CT treated ASB - CT treated actin

\section{Isolation and purification of GAGs from cells}

Cell samples were freeze dried and defatted by washing the samples with chloroform/methanol mixture of (2:1, $1: 1,1: 2(\mathrm{v} / \mathrm{v}))$ each left overnight. The defatted samples (in $1 \mathrm{ml}$ water) were individually subjected to proteolysis at $55^{\circ} \mathrm{C}$ with $10 \%$ of actinase E $(20 \mathrm{mg} / \mathrm{ml}$; Kaken Biochemicals, Tokyo, Japan) for $18 \mathrm{~h}$. After proteolysis, dry urea and dry CHAPS were added to each sample [2 wt \% $(\%, w / v)$ in CHAPS and $8 \mathrm{M}$ in urea]. Particulates were removed from the resulting solutions by passing each through a syringe filter containing a $0.22 \mu \mathrm{m}$ membrane. A Vivapure MINI Q H spin column [Viva Science (Edgewood, NJ)] was prepared by equilibrating with $0.5 \mathrm{ml}$ of $8 \mathrm{M}$ urea containing 2\% CHAPS ( $\mathrm{pH} 8.3$ ). The clarified, filtered samples were loaded onto and run through the Vivapure MINI QH spin columns under centrifugal force $(1000 \times g)$. The columns were first washed with $0.5 \mathrm{ml}$ of $8 \mathrm{M}$ urea containing $2 \% \mathrm{CHAPS}$ at $\mathrm{pH}$ 8.3. The columns were then washed five times with $0.5 \mathrm{ml}$ of $200 \mathrm{mM} \mathrm{NaCl}$. GAGs were released from the spin column by washing 1 time with $0.5 \mathrm{ml}$ of $16 \% \mathrm{NaCl}$. Methanol $(2 \mathrm{ml})$ was added to afford an 80 vol\% (\%,v/v) solution and the mixture was equilibrated at $4^{\circ} \mathrm{C}$ for $18 \mathrm{~h}$. The resulting precipitate was recovered by centrifugation $(2500 \times g)$ for 15 $\mathrm{min}$. The precipitate was recovered by dissolving in $1.0 \mathrm{ml}$ of water. GAG solution was desalted using spin mem- brane (YM-3, 3000 MWCO, Millipore, Bedford, MA). GAGs were recovered and dissolved in $0.5 \mathrm{ml}$ of water, and the recovered GAGs were stored frozen for further analysis.

\section{Enzymatic depolymerization of GAGs}

GAG samples were incubated with chondroitinase ABC (10 milliunits; Seikagaku, Tokyo, Japan) and chondroitinase ACII ( 5 milli-units Seikagaku Corporation, Tokyo, Japan) at $37^{\circ} \mathrm{C}$ for $10 \mathrm{~h}$. The enzymatic products were recovered by the centrifugal filtration (YM-3, Millipore). $\mathrm{CS} / \mathrm{DS}$ disaccharides passed through the filter, were freeze-dried and ready for LC-MS analysis.

\section{Disaccharide composition analysis using liquid chromatography-mass spectrometry (LC-MS)}

Unsaturated disaccharide standards of CS/DS ( $\triangle \mathrm{Di}-0 \mathrm{~S}$ $\Delta$ UA-GalNAc, $\Delta$ Di-4S $\Delta$ UA-GalNAc4S, $\Delta$ Di-6S $\Delta U A-$ GalNAc6S, $\triangle$ Di-UA2S $\triangle$ UA2S-GalNAc, $\Delta$ Di-diSB $\Delta$ UA2SGalNAc4S, $\Delta$ Di-diSD $\triangle$ UA2S-GalNAc6S, $\Delta$ Di-diSE $\Delta U A$ GalNAc4S6S, $\Delta$ Di-triS $\Delta$ UA2S-GalNAc4S6S) were obtained (Seikagaku).

The LC-MS analysis was performed on a LC-MS system (Agilent, LC/MSD trap MS). Solutions A and B for HPLC were $0 \%$ and $75 \%$ acetonitrile, respectively, containing the same concentration of $15 \mathrm{mM}$ Hexylamine (HXA) and $100 \mathrm{mM}$ 1,1,1,3,3,3,-hexafluoro 2-propanol (HFIP). The flow rate was $100 \mu \mathrm{l} / \mathrm{min}$. The separation was performed on an ACQUITY UPLCTM BEH C18 column (Waters, $2.1 \times$ $150 \mathrm{~mm}, 1.7 \mu \mathrm{m})$ at $45^{\circ} \mathrm{C}$ using solution A for $10 \mathrm{~min}$, followed by a linear gradient from 10 to $40 \mathrm{~min}$ of $0 \%$ to $50 \%$ solution $\mathrm{B}$. The column effluent entered the source of the ESI-MS for continuous detection by MS. The electrospray interface was set in positive ionization mode with the skimmer potential $40.0 \mathrm{~V}$, capillary exit $40.0 \mathrm{~V}$ and a source of temperature of $350^{\circ} \mathrm{C}$ to obtain maximum abundance of the ions in a full scan spectra (150$1500 \mathrm{Da}, 10$ full scans/s). Nitrogen was used as a drying (8 liters/min) and nebulizing gas (40 p.s.i.). The data were collected by UV and mass, respectively. Extracted ion chromatography (EIC) was processed using Bruck software.

\section{Statistical analysis}

Statistical significance of the data was analyzed using Instat software. Unless stated otherwise, one-way ANOVA with Tukey-Kramer post-test was performed with $\mathrm{p}<0.05$ considered significant. At least three independent experiments were performed for each analysis, and technical replicates of each sample were performed. In the figures, *** represents $\mathrm{p}<0.001,{ }^{* *} \mathrm{p}<0.01$, and ${ }^{*} \mathrm{p}<0.05$. 


\section{Results \\ Chloroquine reduces ASB activity}

ASB activity post exposure to chloroquine $(50 \mathrm{nM} \times 24$ hours) was measured in the human placental, bronchial epithelial, and CVC cells. In the placental cells, ASB activity post-chloroquine exposure declined by $50 \%$, from a baseline of $83.5 \pm 9.8 \mathrm{nmol} / \mathrm{mg} / \mathrm{h}$ to $41.6 \pm 3.6 \mathrm{nmol} / \mathrm{mg} /$ $\mathrm{h}$ (Figure 1A). In the $\mathrm{C} 38$ and IB3-1 cells, progressive decline in ASB activity followed exposure to increasing concentrations of chloroquine (Figure 1B; $\mathrm{p}<0.0001$ for linear trend). When ASB was silenced by siRNA in the CVC cells, the decline in ASB activity was greater than the decline following chloroquine, but both were significant (Figure 1C; $\mathrm{p}<0.001$, 1-way ANOVA with Tukey-Kramer post-test). The decline in ASB activity following chloroquine was proportional to the baseline activity, with greatest decline in the CVC that had the highest initial level (Figure 1D).

\section{Chloroquine increases total sulphated glycosaminoglycans (sGAG) and chondroitin-4-sulphate (C4S)}

Marked increase in sGAG followed exposure to chloroquine in the placental, IB3-1, C38, and CVC cells (Figures 2A, B, C), consistent with reduced ASB activity leading to accumulation of sGAG. When cell lysates were immunoprecipitated with the $\mathrm{C} 4 \mathrm{~S}$ antibody and the resulting sGAG measured by the Blyscan assay (Figures 3A, B, C), it was apparent that the increase in sGAG was largely attributable to increase in $\mathrm{C} 4 \mathrm{~S}$, and was consistent with a specific effect on reduction of ASB activity by chloroquine. The increases in sGAG and C4S with increasing concentrations of chloroquine showed a linear trend in the $\mathrm{C} 38$ and IB3-1 cells (Figure 3B; $\mathrm{p}<0.0001$ ). In the CVC, increases in sGAGs and C4S following chloroquine were somewhat less than following ASB silencing, but both were significant (Figure 3C; p < 0.001, 1-way ANOVA with TukeyKramer post-test). ASB activity was inversely correlated with C4S content in the four cell lines tested (Figure 3D).

\section{Disaccharide composition of CVC, IB3-I and C38 cells}

Disaccharide composition of treated and control CVC is listed in Table 1. Because of partial peak overlap, quantification relied on MS using a method previously demonstrated for heparan sulfate disaccharide analysis [18]. Figure 4 (also see Additional File 1) is extracted ion chromatography (EIC) of CS/DS disaccharide analysis of CVC cells. The percentage of $\mathrm{C} 4 \mathrm{~S}$ increased significantly in the CVC.

The chondroitin sulphate content in the C38 and IB3-1 cells that were grown to confluency in a T75 flask was calculated by a quantitative method for HPLC. The peak areas of CS disaccharide standards in UV chromatography are functions of their amounts. Based on the linear relation between the UV peak areas, the amount of disaccha- rides in C38 and IB3-1 cells was calculated. In the C38 cells, the CS content was $70 \mu \mathrm{g}$ and increased to $310 \mu \mathrm{g}$ following chloroquine. In the IB3-1 cells, the chondroitin sulfate increased from $330 \mu \mathrm{g}$ to $650 \mu \mathrm{g}$ following chloroquine. In the C38 and IB3-1 cells, the percentage of C4S disaccharides varied less following chloroquine than in the CVC.

\section{Confocal imaging of ASB in CVC and bronchial epithelial cells}

Confocal images of ASB were obtained following fluorescent immunostaining, in which ASB appears red and $\beta$ actin appears green (Figure 5A, B). The presence of ASB was demonstrated along the cell periphery, consistent with membrane localization. Nuclear and cytoplasmic localization were also evident. The membrane localization was unexpected, since ASB had been regarded as solely a lysosomal enzyme. In the primary bronchial epithelial cells (BEC), fluorescent immunostaining for ASB was markedly reduced following exposure to chloroquine (Figure 5C) vs. untreated control (Figure 5D), and was evident along the cell periphery.

\section{ASB activity, ASB protein content, mRNA expression, and total sGAG}

The ASB protein content in the placental cells was measured by a Fast Activated Cell-based ELISA (FACE) and compared with the ASB activity after exposure to chloroquine $50 \mathrm{nM}$ for 24 hours. ASB activity declined from 83.5 \pm 9.8 to $41.6 \pm 3.6 \mathrm{nmol} / \mathrm{mg}$ protein $/ \mathrm{hr}$ (to $49.8 \%$ of baseline), and ASB protein content declined to $47.6 \pm 5.2 \%$ of the baseline, indicating the close correspondence between the activity measurement and the FACE assay.

Placental cells were treated with chloroquine $50 \mathrm{nM} \times 24$ hours and fresh media added at 24 and 48 hours. Spent media were collected at 24, 48, and 72 hours, and ASB activity (Figure 6A) and total sGAG were measured (Figure $6 B)$. ASB activity nadir was at 24 hours, with return to baseline by 72 hours. Inversely, the sGAG content peaked at 24 hours and returned to baseline by 72 hours. These findings indicate that the effects of chloroquine exposure on ASB activity and sGAG content are prolonged beyond the time of direct exposure, but have dissipated by 72 hours.

Following chloroquine treatment in the C38 and IB3-1 cells, the mRNA expression of ASB declined significantly, in contrast to $\beta$-actin expression (Figure 6C). ASB cycle threshold (CT) in untreated C38 cells was $29.7 \pm 0.2$ compared to CT of $32.4 \pm 0.4$ in the chloroquine-treated cells, with $\beta$-actin values of $30.3 \pm 0.9$ and $29.4 \pm 0.2$. Similarly, in the IB3-1 cells, CT for ASB in control cells was $31.0 \pm$ 0.2 and increased to $33.8 \pm 1.3$ following chloroquine exposure, with $\beta$-actin values of $29.5 \pm 0.3$ and $30.1 \pm 0.4$. 
A.

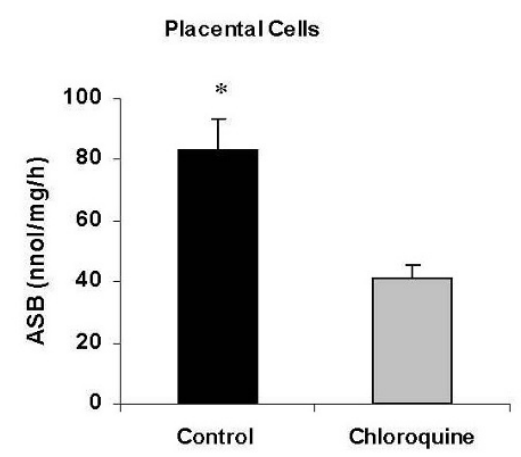

B.

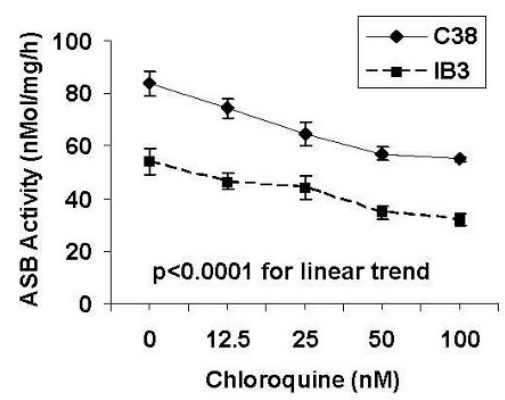

c.

cve

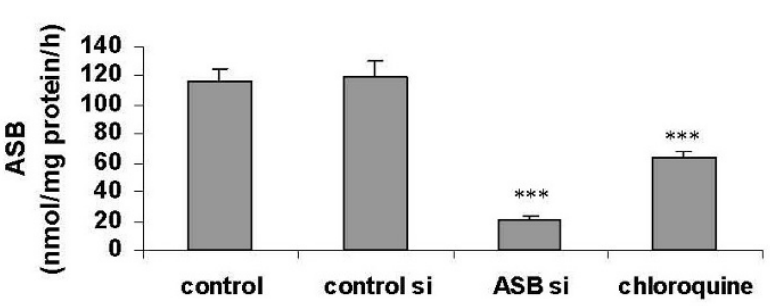

D.

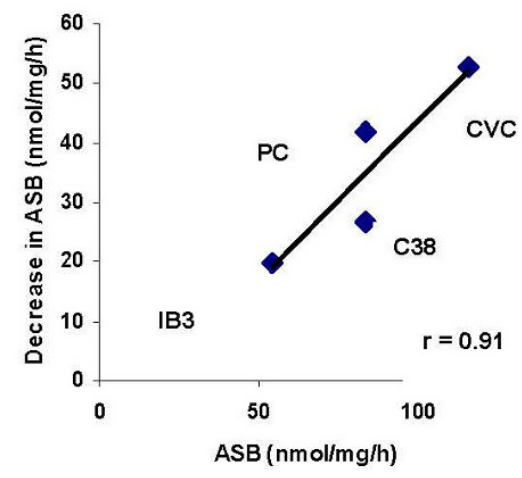

Figure I

ASB activity declines following exposure to chloroquine (CQ). ASB activity declined in the placental fibroblasts following chloroquine exposure (Panel $\mathbf{A} ; \mathrm{P}=0.02$, unpaired t-test, two-tailed). ASB activity was significantly higher in the C38 than in the IB3-I cells. Following exposure to increasing concentrations of chloroquine, the ASB activity declined linearly in both cell lines (Panel B; $p<0.000$ I, I-way ANOVA for linear trend; $r^{2}=0.89$ for C38 and $r^{2}=0.86$ for IB3-I). In the CVC, chloroquine exposure produced significant reduction in ASB activity (Panel C; $\mathrm{p}<0.00 \mathrm{I}$, I-way ANOVA with Tukey-Kramer post-test). Following ASB silencing by siRNA, the ASB activity was reduced more than by chloroquine. The extent of reduction in ASB activity is less when the baseline ASB activity is less, as demonstrated by the direct correlation between the change in ASB activity and the baseline ASB activity (Panel $\mathbf{D} ; r=0.91$ ). [con si = control siRNA; $A S B$ si = ASB siRNA; CVC = cerebrovascular cells; $\mathrm{PC}=$ placental cells; $\mathrm{ASB}=$ arylsulphatase $\mathrm{B}]$. 


\section{Placental Cells}

A.

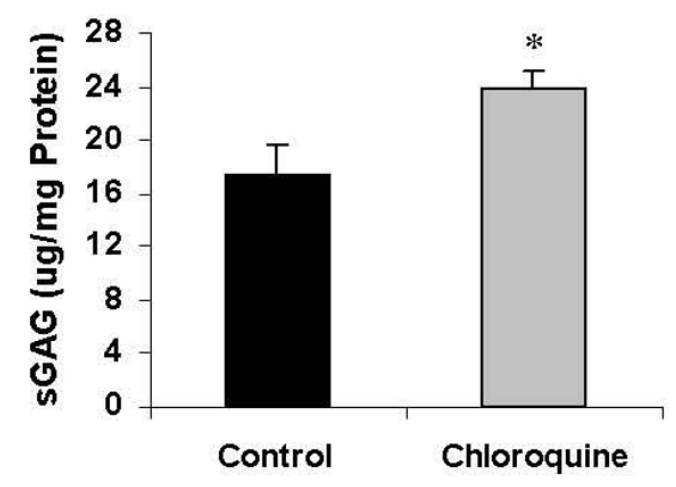

B.

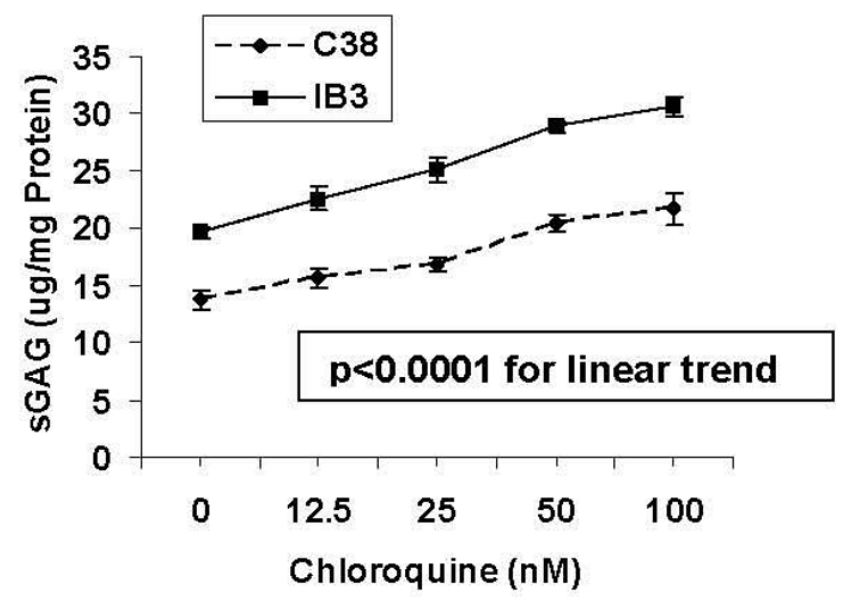

C.

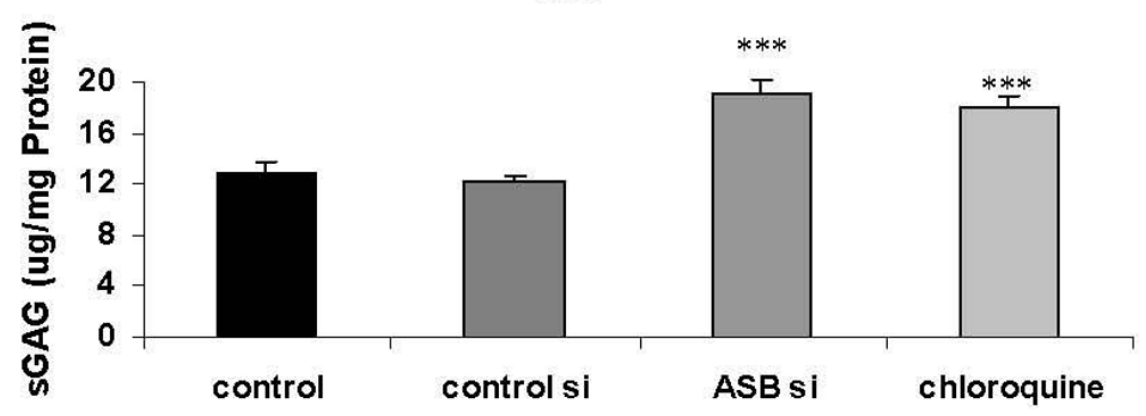

\section{Figure 2}

Increased total sulphated glycosaminoglycan (sGAG) content following chloroquine exposure. In the placental cells, the sGAG content increased significantly following chloroquine (50 nM $\times 24$ hours) (Panel A; $p=0.02$, unpaired t-test, two-tailed). Similarly, the sGAG content increased linearly in response to exposure to increasing concentrations of chloroquine (Panel B; $p<0.000$ I, I-way ANOVA for linear trend; $r^{2}=0.92$ for C38 cells and $r^{2}=0.96$ for IB3-I cells). For the CVC, the increase in sGAG was significant following chloroquine $(50 \mathrm{nM} \times 24$ hours) and ASB siRNA ( $\times 24$ hours) (Panel C; $\mathrm{P}<$ $0.00 \mathrm{I}$, I-way ANOVA with Tukey-Kramer post-test). [con si = control siRNA; ASB si = ASB siRNA; CVC = cerebrovascular cells; $\mathrm{PC}=$ placental cells; $\mathrm{ASB}=$ arylsulphatase $\mathrm{B}]$. 
Placental Cells

A.

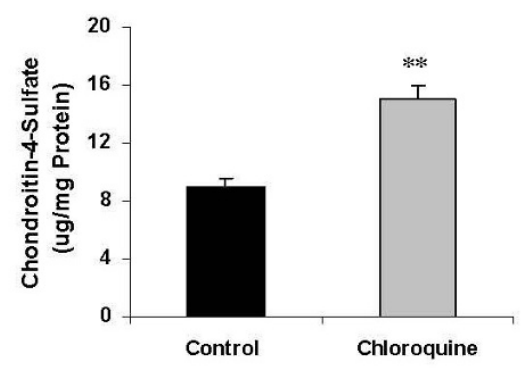

B.

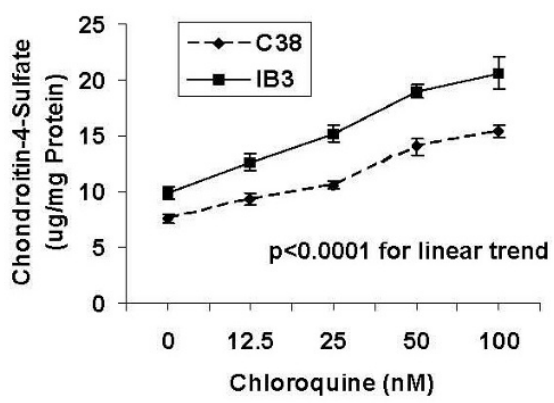

c.

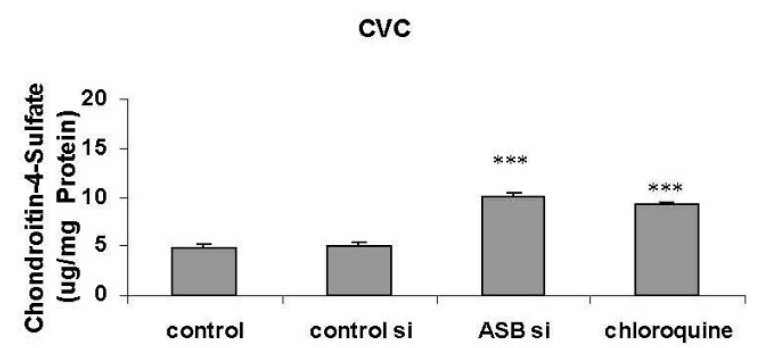

D.

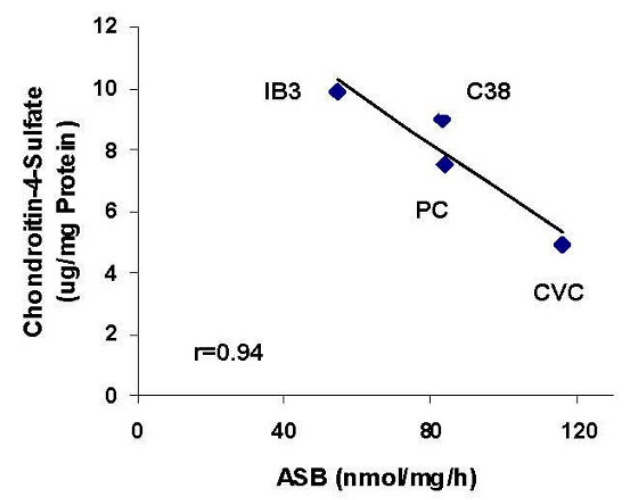

\section{Figure 3}

Increased chondroitin-4-sulphate (C4S) content following chloroquine exposure. The concentration of C4S increased significantly following exposure to increasing concentrations of chloroquine in the placental cells for 24 hours (Panel $\mathbf{A} ; \mathrm{P}=0.002$, unpaired t-test, two-tailed) and in the C38 and IB3-I cells for 24 hours (Panel B; $P<0.000$ I, I-way ANOVA for linear trend; $r^{2}=0.96$ for C38 cells and $r^{2}=0.96$ for IB3-I cells). For the CVC cells, the increase in C4S was significant following chloroquine $(50 \mathrm{nM} \times 24$ hours) and ASB siRNA ( $\times 24$ hours) (Panel C; $\mathrm{P}<0.00$ I, I-way ANOVA with Tukey-Kramer post-test). The decline in ASB activity was inversely correlated with the increase in C4S content $(\mathbf{P a n e l} \mathbf{D} ; r=0.94)$. [con si = control siRNA; ASB si = ASB siRNA; CVC = cerebrovascular cells; $P C=$ placental cells $]$. 


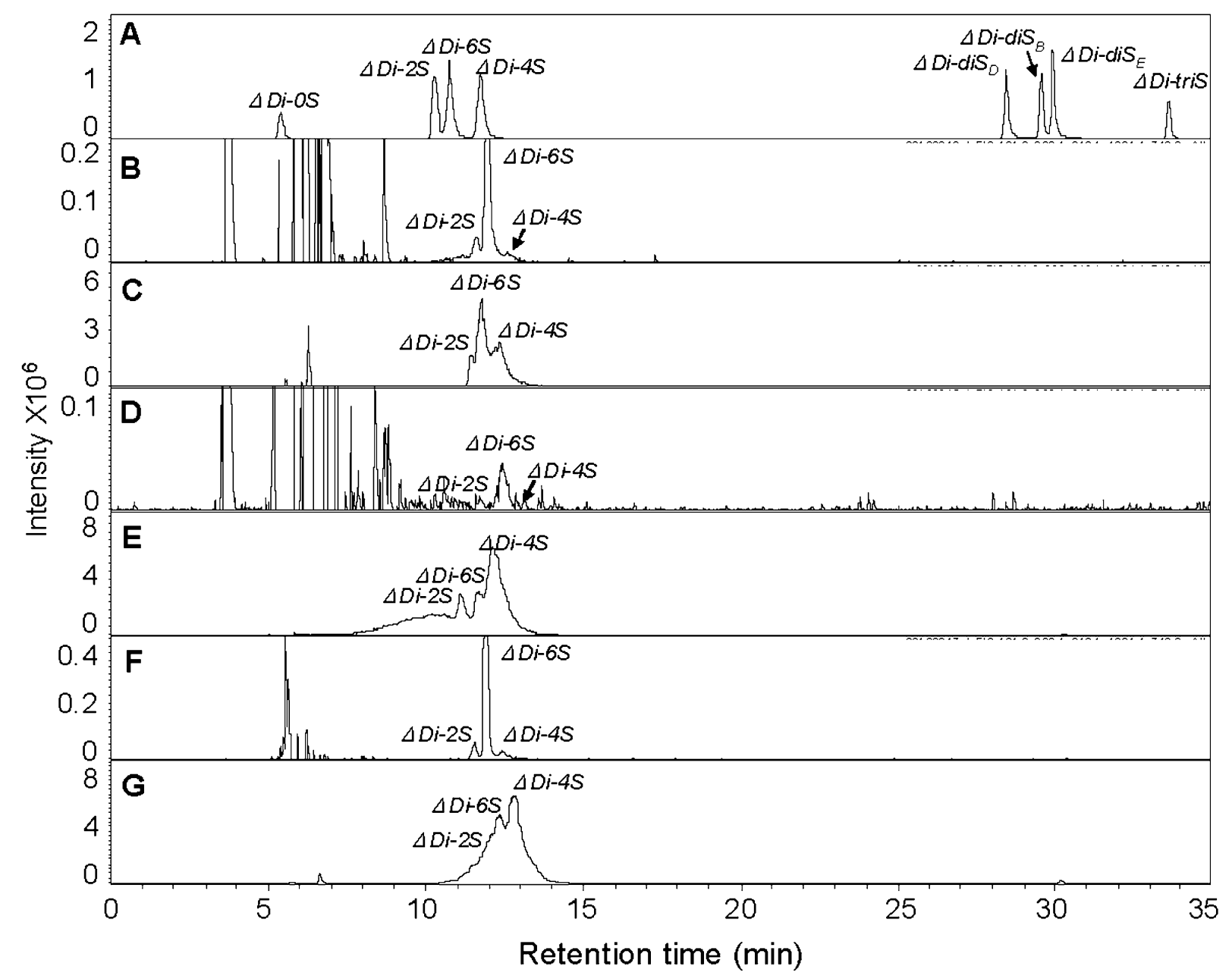
A: CS std.
B: CVC cont-1
C: CVC chl-1
D: CVC cont-2
E: CVC chl-2
F: CVC cont-3
G: CVC chl-3

Figure 4

Extracted ion chromatography (EIC) representation of disaccharide composition in cerebrovascular cells before and after exposure to chloroquine. The HPLC system used resolves the eight CS disaccharide standards (Panel A). Despite the variability of retention time due to variable quantities of residual buffer salts, peak identity was easily confirmed by co-injection with single known CS disaccharide standards as well as from their MS (see Additional File I) or by MS/MS spectra. CVC controls (Panels B, D, and F) and CVC after chloroquine treatment (Panels C, E, and G) are shown. The chloroquine-treated CVC demonstrate marked increase in the peak for C4S disaccharide $(\triangle \mathrm{Di}-4 \mathrm{~S})$ following chloroquine exposure (Panels E and G vs. Panel F). Additional peaks observed early (3-8 $\mathrm{min}$ ) in the chromatograms $B$, D, and F and well separated from the sulpho-group containing CS standards are residual contaminants from cells and media and do not interfere with the analysis. 
Table I: CS/DS disaccharide composition of cerebrovascular cells*

\begin{tabular}{lcccccccc}
\hline Composition (\%) & $\Delta$ Di-OS & $\Delta$ Di-UA2S & $\Delta$ Di-6S & $\Delta$ Di-4S & $\Delta$ Di-diSD & $\Delta$ Di-diS & $\Delta$ Di-diSE & $\Delta$ Di-triS \\
\hline CVC-cont-I & n.d. & 8.5 & 84.3 & 7.2 & n.d. & n.d. & n.d. & n.d. \\
CVC-1 & n.d. & 10.3 & 43.9 & 45.2 & 0.22 & 0.08 & 0.3 & n.d. \\
CVC-cont-2 & n.d. & 7 & 90 & 3 & n.d. & n.d. & n.d. & n.d. \\
CVC-2 & n.d. & 17.3 & 16.2 & 66 & 0.09 & 0.02 & 0.39 & n.d. \\
CVC-cont-3 & n.d. & 8.1 & 84.9 & 7 & n.d. & n.d. & n.d. & n.d. \\
CVC-3 & n.d. & 24.1 & 22.9 & 52.2 & 0.12 & 0.03 & 0.65 & n.d. \\
\hline
\end{tabular}

$* \mathrm{CS}=$ chondroitin sulphate; $\mathrm{DS}=$ dermatan sulphate; CVC = cerebrovascular cells; cont = control; CVC-I, CVC-2, CVC-3 = chloroquine-treated; n.d. $=$ not detected

DDi-0S: 2-acetamido-2-deoxy-3-O-(b-D-xylo-hex-4-enopyranosyluronic acid)-D-galactose

DDi-4S: 2-acetamido-2-deoxy-4-O-sulphosulpho-3-O-(b-D-xylo-hex-4-enopyranosyluronic acid)-D-galactose

DDi-6S: 2-acetamido-2-deoxy-6-O-sulpho-3-O-(b-D-xylo-hex-4-enopyranosyluronic acid)-D-galactose

DDi-UA2S: 2-acetamido-2-deoxy-3-0-(2-O-sulpho-b-D-xylo-hex-4-enopyranosyluronic acid)-D-galactose

DDi-diSB: 2-acetamido-2-deoxy-4-O-sulpho-3-O-(2-O-sulpho-b-D-xylo-hex-4-enopyranosyluronicacid)-D-galactose

DDi-diSD: 2-acetamido-2-deoxy-6-O-sulpho-3-O-(2-O-sulpho-b-D-xylo-hex-4-enopyranosyluronicacid)-D-galactose

DDi-diSE: 2-acetamido-2-deoxy-4,6-di-O-sulpho-3-O-(b-D-xylo-hex-4-enopyranosyluronic acid)-D-galactose

DDi-triS: 2-acetamido-2-deoxy-4,6-di-O-sulpho-3-O-(2-O-sulpho-b-D-xylo-hex-4-enopyranosyluronic acid)-D-galactose acid)-D-galactose

These results indicate a 12-fold decrease in ASB mRNA expression in the $\mathrm{C} 38$ cells and a 5 -fold decrease in the IB3-1 cells following chloroquine exposure.

\section{Discussion}

The study findings indicate that exposure to chloroquine reduced the ASB activity and expression and, correspondingly, increased the content of chondroitin-4-sulphate, as well as total sGAGs, in human placental, bronchial, and cerebrovascular cells. C4S has been identified as the cell surface molecule associated with adherence of infected erythrocytes to Saimiri brain and human lung endothelial cells, as well as placental cells [2]. Since low-sulphated chondroitin sulphate has been implicated in the increased adherence of $P$. falciparum-infected red blood cells in the human placenta [7-12], the in vitro findings in this report may be relevant to the mechanism of clinical infection, particularly if placental infections are attributable to the expression of novel variant surface antigens that bind preferentially to C4S [19]. Reduced ASB activity and the associated increase in $\mathrm{C} 4 \mathrm{~S}$ sulphation in human vascular or bronchial cells post-chloroquine may hinder the attachment of parasite-infected erythrocytes in vivo.

The low-sulphated chondroitin sulphate proteoglycan receptors of placenta are found predominantly in the intervillous space, and parasite-infected red blood cells sequester in the human placenta through attachment to C4S. The major attachment to C4S is reported to be by the Plasmodium falciparum erythrocyte membrane protein 1 (PfEMP1), encoded by the var2csa gene [20].

Chloroquine has been found to accumulate in lysosomes, and by effects on lysosomal $\mathrm{pH}$, its exit from the lysosome is prevented $[21,22]$. Since ASB is also found in the lysosome, chloroquine, by effects on lysosomal $\mathrm{pH}$, may reduce the lysosomal ASB activity in vivo, since ASB functions optimally at low $\mathrm{pH}$. The study finding that chloroquine exposure reduced the mRNA expression of ASB, as well as the ASB protein and activity in the in vitro assay, indicates that chloroquine directly affects mRNA content. Study data (not shown) demonstrated that activity of the lysosomal enzyme galactose-6-sulphatase (GALNS) also declined post-chloroquine exposure in the $\mathrm{CVC}$ and placental cells, although the decline was not as much as that found in ASB activity.

Chloroquine has been used for treatment of malarial infections for many decades. The mechanism of action of chloroquine has been attributed to various effects, including entrapment in the parasite's food vacuole, inhibition of haem polymerase with accumulation of the toxic $\mathrm{Fe}(\mathrm{II})$-protoporphyrin IX-chloroquine complex that disrupts membrane function and leads to parasite autodigestion, or interference with nucleic acid biosynthesis by intercalation with parasitic DNA [21-23]. The current study findings neither refute nor support these mechanisms, but suggest an additional biochemical mechanism to explain the effect of chloroquine.

The study data suggest that development of resistance to chloroquine may be, at least in part, attributable to the presence of extra-lysosomal ASB, which would be unaffected by chloroquine that is accumulated and sequestered in the lysosomes. Also, since the decline in ASB activity was less when the baseline ASB activity was less, the effectiveness of chloroquine might be expected to diminish as ASB activity declined.

Further attention to the effects of ASB on sulphation of C4S may facilitate development of innovative anti-malarial therapies. Improved understanding of the mechanism 

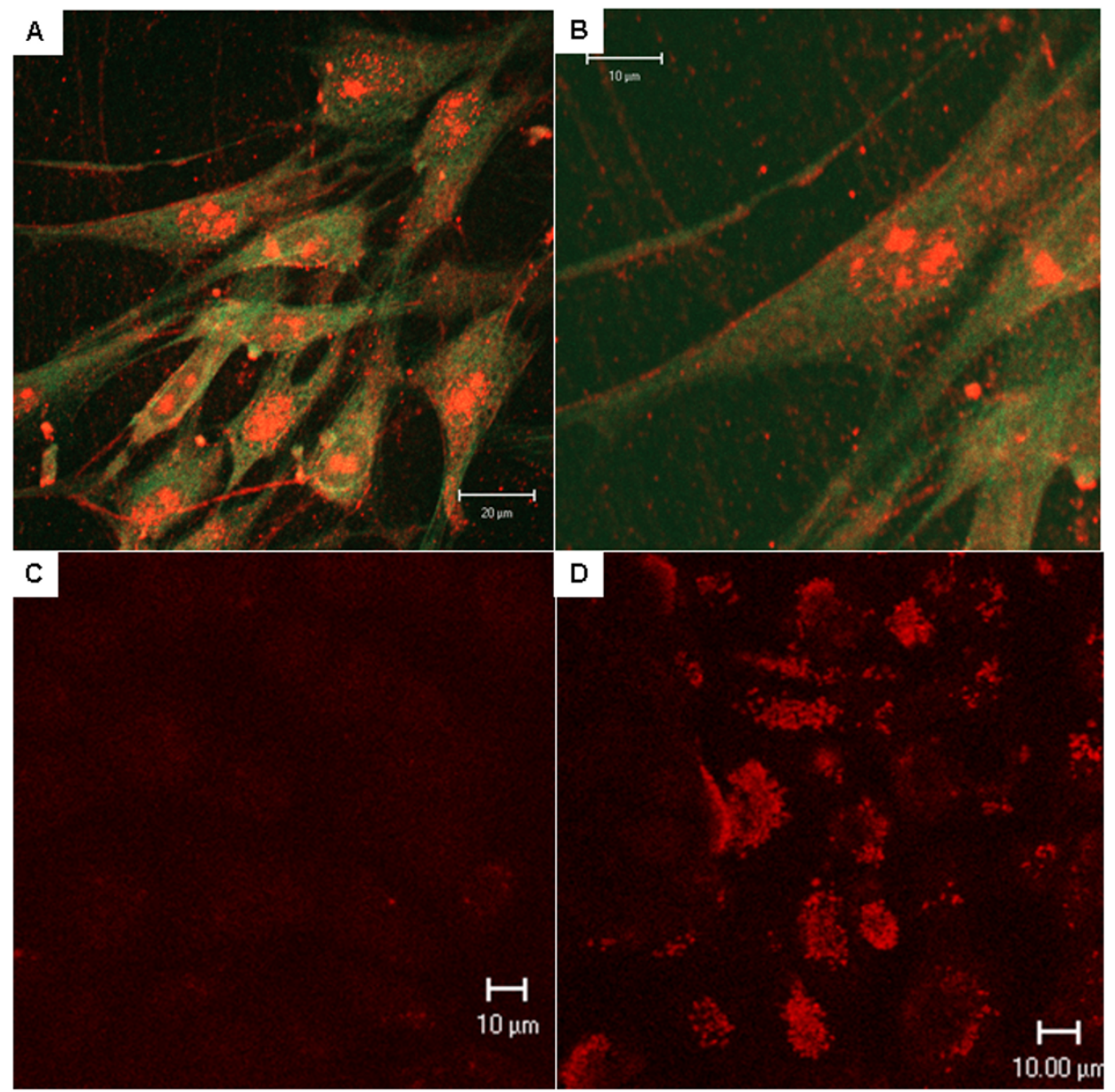

\section{Figure 5}

Confocal microscopy demonstrates cell surface localization of ASB. Confocal microscopy demonstrates the presence of peripheral localization of ASB in the CVC, as well as cytoplasmic and nuclear localization. ASB is stained red, and $\beta$ actin is stained green (Panels A, B). In primary bronchial epithelial cells, exposure to chloroquine $(50 \mathrm{nM} \times 24 \mathrm{hours}) \mathrm{pro}$ duced marked reduction in ASB fluorescent immunostaining (Panel $\mathbf{C})$, compared to untreated control (Panel D). [CVC = cerebrovascular cells; ASB = arylsulphatase B; BEC = bronchial epithelial cells].

of action of chloroquine might provide new insight into mechanisms of resistance, leading to improved therapeutic approaches to what remains one of the most prevalent and deadly infectious diseases.

\section{Conclusions}

Study data demonstrate that exposure of human placental, bronchial, and cerebrovascular cells in tissue culture to chloroquine leads to reduced mRNA and protein expression and activity of the enzyme arylsulphatase B, and to increased cellular content of chondroitin-4-sulphate, as well as total sulphated glycosaminoglycans. Since the degree of sulphation of chondroitin-4-sulphate has been associated with the attachment of $P$. falciparum- infected erythrocytes to the intervillous cells of the placenta, chloroquine-induced decline in ASB activity, with the accompanying increase in chondroitin-4-sulphation, may produce its anti-malarial effect. Extra-lysosomal ASB and the decline in further reduction of ASB activity at lower activity levels may contribute to development of resistance to chloroquine.

\section{Abbreviations}

ASB: arylsulphatase B; BEC: bronchial epithelial cell; C4S: chondroitin-4-sulphate; CVC: cerebrovascular cell; CQ: chloroquine; CT: cycle threshold; EIC: extracted ion chromatography GAG: glycosaminoglycan; LC-MS: liquid chromatography-mass spectrometry; MPS: mucopolysac- 
A.

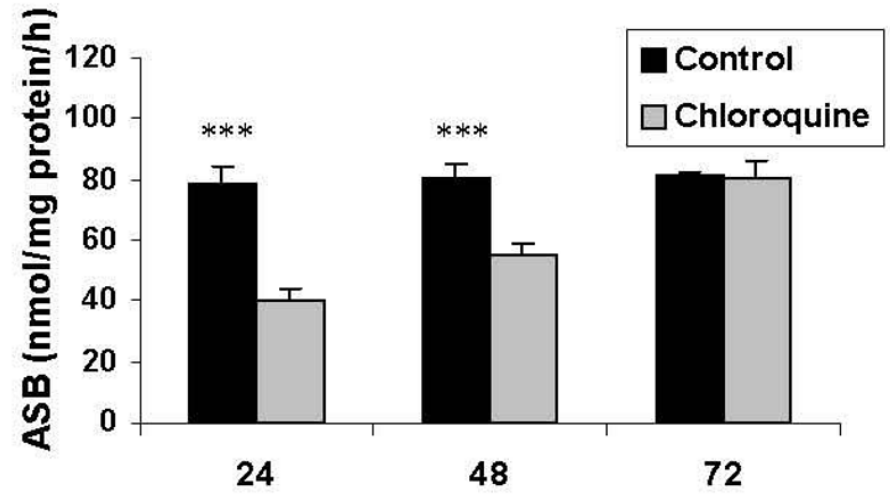

Hours

B.

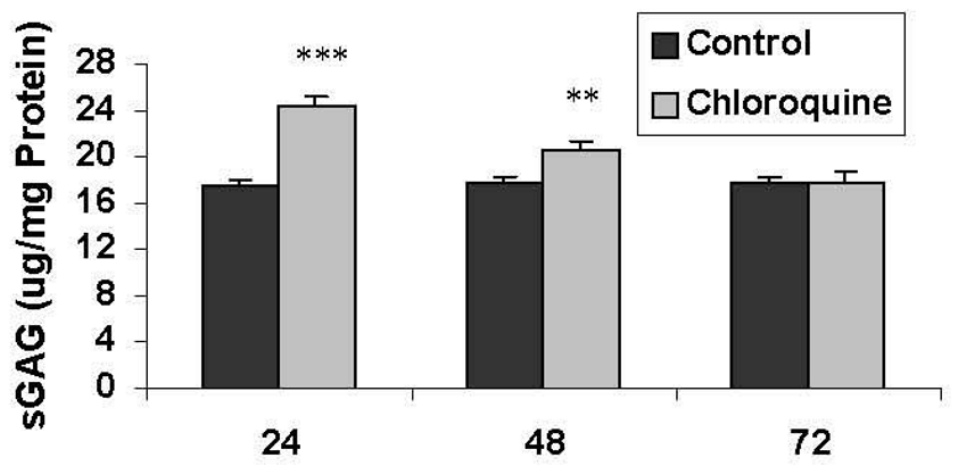

Hours

C.

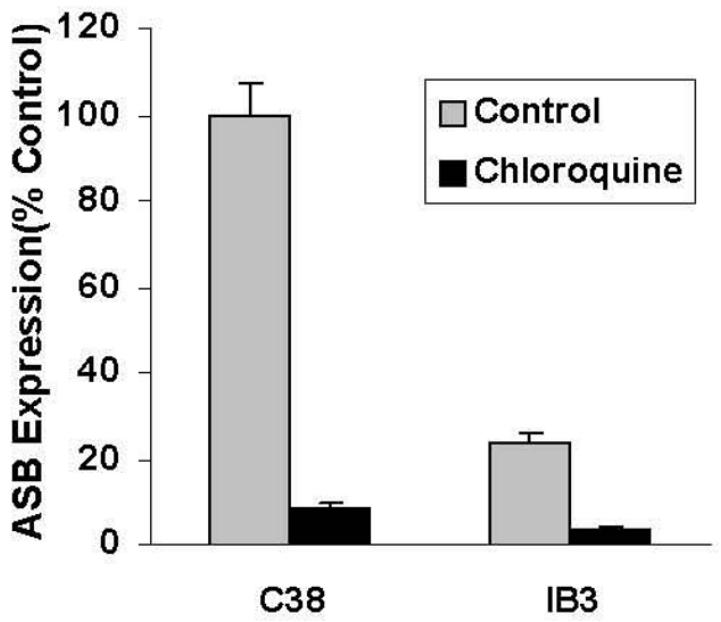

Figure 6

Relationship between ASB activity and total sGAG following chloroquine exposure over 72 hours. Chloroquine $(50 \mathrm{nM})$ was administered for 24 hours, the spent media removed, and fresh media without chloroquine was supplied at 24 and 48 hours. ASB activity (Panel A) and total sGAG (Panel B) were measured in spent media at 24, 48, and 72 hours, as shown. ASB activity rose from the nadir at 24 hours and returned to baseline by 72 hours $(p<0.00 \mathrm{I}$ at 24 and 48 hours; I-way ANOVA with Tukey-Kramer post-test). Inversely, the sGAG content peaked at 24 hours and returned to baseline by 72 hours $(p<0.00 \mathrm{I}$ at 24 hours, $\mathrm{p}<0.0 \mathrm{I}$ at 48 hours; I-way ANOVA with Tukey-Kramer post-test). QPCR demonstrated less baseline mRNA expression of ASB in the IB3-I cells than in the C38 cells (Panel C), and declines in both cell lines following exposure to chloroquine (50 $\mu \mathrm{M} \times 24$ hours). Cycle threshold of ASB was calculated in comparison to cycle threshold of $\beta$-actin, which varied only from 29.36 to 30.27 . 
charidosis; QPCR: quantitative polymerase chain reaction; sGAG: sulphated glycosaminoglycan; RBC: red blood cell; PfEMB1: Plasmodium falciparum erythrocyte membrane protein- 1 .

\section{Competing interests}

The authors declare that they have no competing interests.

\section{Authors' contributions}

SB planned experiments with JKT, performed the experiments, and prepared many of the figures. JKT planned experiments with $\mathrm{SB}$, performed confocal microscopy, and prepared the manuscript. ZZ, RJL and KS performed the isolation and purification of the GAGs from the cells and the LC-MS analysis to determine the disaccharide composition of the GAGs. They wrote the sections of the manuscript, the table, and the figures that present these methods and results. All authors read and approved the final manuscript.

\section{Additional material}

\section{Additional file 1}

Detailed mass spectrometry data of cerebrovascular cell disaccharides. The file contains detailed analysis of the cerebrovascular cell disaccharides that were present following isolation and purification of the cellular $s G A G$, followed by their enzymatic depolymerization, and separation and detection by LC-MS, as detailed in the Methods. Figure 4A presents peaks of the disaccharide standards, including $\triangle D i-0 S, \triangle D i-U A 2 S, \triangle D i-6 S$, $\triangle D i-4 S, \triangle D i$-diSD, $\triangle D i$-diSB, $\triangle D i$-diSE, and $\triangle D i$-triS. Figures $4 B-4 G$ present mass spectra for $\triangle D i-O S, \triangle D i-U A 2 S$, and $\triangle D i-6 S$, in the control $(4 B, 4 F)$ or chloroquine-treated $(4 C, 4 E, 4 G)$ cerebrovascular cells, with demonstrable changes in amplitude of the peaks for the disaccharides of major interest in this report.

Click here for file

[http://www.biomedcentral.com/content/supplementary/14752875-8-303-S1.PDF]

\section{Acknowledgements}

The authors acknowledge the assistance of Mei Ling Chen, M.D. with confocal microscopy. Funding sources include NIH grants GM38060 and HLIOI72I to RJL.

\section{References}

I. Rogerson S], Brown GV: Chondroitin sulfate $\mathbf{A}$ as an adherence receptor for Plasmodium falciparum-infected erythrocytes. Parasitol Today 1997, 13:70-75.

2. Beeson JG, Chai W, Rogerson SJ, Lawson AM, Brown GV: Inhibition of binding of malaria-infected erythrocytes by a tetradecasaccharide fraction from chondroitin sulfate A. Infect Immun 1998, 66:3397-3402.

3. Muthusamy A, Achur RN, Valiyaveettil M, Botti JJ, Taylor DW, Leke RF, Gowda DC: Chondroitin sulfate proteoglycan but not hyaluronic acid is the receptor for the adherence of Plasmodium falciparum-infected erythrocytes in human placenta, and infected red blood cell adherence up-regulates the receptor expression. Am J Pathol 2007, 170:1989-2000.

4. Achur RN, Agbor-Enoh ST, Gowda DC: Rat spongiotrophoblastspecific protein is predominantly a unique low sulfated chondroitin sulfate proteoglycan. J Biol Chem 2006, 28 I:32327-32334.
5. Beeson JG, Andrews KT, Boyle M, Duffy MF, Choong EK, Byrne T], Chesson JM, Lawson AM, Chai W: Structural basis for binding of Plasmodium falciparum erythrocyte membrane protein I to chondroitin sulfate and placental tissue and the influence of protein polymorphisms on binding specificity. J Biol Chem 2007, 282:22426-22436.

6. Fried M, Domingo GJ, Gowda CD, Mutabingwa TK, Duffy PE: Plasmodium falciparum: Chondroitin sulfate $A$ is the major receptor for adhesion of parasitized erythrocytes in the placenta. Exp Parasitol 2006, I I 3:36-42.

7. Muthusamy A, Achur RN, Valiyaveettil M, Gowda DC: Plasmodium falciparum: adherence of the parasite-infected erythrocytes to chondroitin sulfate proteoglycans bearing structurally distinct chondroitin sulfate chains. Exp Parasitol 2004, I07: I83-188.

8. Achur RN, Valiyaveettil M, Alkhalil A, Ockenhouse CF, Gowda DC: Characterization of proteoglycans of human placenta and identification of unique chondroitin sulfate proteoglycans of the intervillous spaces that mediate the adherence of Plasmodium falciparum-infected erythrocytes to the placenta. J Biol Chem 2000, 275:40344-40356.

9. Alkhalil A, Achur RN, Valiyaveettil M, Ockenhouse CF, Gowda DC: Structural requirements for the adherence of Plasmodium falciparum-infected erythrocytes to chondroitin sulfate proteoglycans of human placenta. I Biol Chem 2000, 275:40357-40364.

10. Achur RN, Valiyaveettil M, Gowda DC: The low sulfated chondroitin sulfate proteoglycans of human placenta have sulfate group-clustered domains that can efficiently bind Plasmodium falciparum-infected erythrocytes. J Biol Chem 2003, 278: $11705-11713$.

II. Muthusamy A, Achur RN, Bhavanandan VP, Fouda GG, Taylor DW, Gowda DC: Plasmodium falciparum-infected erythrocytes adhere both in the intervillous space and on the villous surface of human placenta by binding to the low-sulfated chondroitin sulfate proteoglycan receptor. Am J Pathol 2004, 164:2013-2025.

12. Achur RN, Muthusamy A, Madhunapantula SV, Gowda DC: Binding affinity of Plasmodium falciparum-infected erythrocytes from infected placentas and laboratory selected strains to chondroitin 4-sulfate. Mol Biochem Parasitol 2008, I 59:79-84.

13. Bhattacharyya S, Tobacman JK: Increased arylsulfatase B activity in cystic fibrosis cells following correction of CFTR. Clin Chim Acta 2007, 380: I22-127.

14. Bhattacharyya S, Kotlo K, Shukla S, Danziger RS, Tobacman JK: Distinct effects of $\mathbf{N}$-acetylgalactosamine-4-sulfatase and galactose-6-sulfatase expression on chondroitin sulfates. J Biol Chem 2008, 283:9523-9530.

15. Bhattacharyya S, Solakyildirim K, Zhang Z, Chen ML, Linhardt RJ, Tobacman JK: Cell-bound IL-8 increases in bronchial epithelial cells following arylsulfatase B silencing. Am J Respir Cell Mol Biol in press.

16. Bhattacharyya S, Tobacman JK: Arylsulfatase B regulates colonic epithelial cell migration by effects on MMP9 expression and RhoA activation. Clin Exp Metastasis 2009, 26:535-545.

17. Bhattacharyya $S$, Tobacman JK: Steroid sulfatase, arylsulfatases $A$ and $B$, galactose 6-sulfatase, and iduronate sulfatase in mammary cells and effects of sulfated and non-sulfated estrogens on sulfatase activity. J Steroid Biochem Mol Biol 2006, 103:20-34.

18. Zhang Z, Xie J, Liu H, Liu J, Linhardt RJ: Quantification of heparan sulfate and heparin disaccharides using ion-pairing, reversedphase, microflow, high performance liquid chromatography coupled with electrospray ionization trap mass spectrometry. Anal Chem 2009, 81 :4349-4355.

19. Serghides L, Patel SN, Ayi K, Kain KC: Placental chondroitin sulfate A-binding malarial isolates evade innate phagocytic clearance. J Infect Dis 2006, 194:133-139.

20. Duffy MF, Maier AG, Byrne TJ, Marty AJ, Elliott SR, O'Neill MT, Payne PD, Rogerson SJ, Cowman AF, Crabb BS, Brown GV: VAR2CSA is the principal ligand for chondroitin sulfate $A$ in two allogeneic isolates of Plasmodium falciparum. Mol Biochem Parasitol 2006, 148: I 17-124.

21. Sugioka Y, Suzuki M, Sugioka K, Nakano M: A ferriprotoporphyrin IX-chloroquine complex promotes membrane phospholipid peroxidation. FEBS Letters 223:25I-254. 
22. Krogstad DJ, Schlesinger PH: The basis of antimalarial action: non-weak base effects of chloroquine on acid vesicle $\mathrm{pH}$. $\mathrm{Am}$ J Trop Med Hyg 1987, 36:213-2I0.

23. Shapiro TA, Goldberg DE: Chemotherapy of Protozoal Infections: Malaria. In Goodman and Gillman's Pharmacological Basis of Therapeutics Volume Chaper 39. I Ith edition. Edited by: Brunton LL, Lazo JS, Parker KL. New York, NY, USA: McGraw-Hill Companies, Inc; 2008:102I-1048.

Publish with Bio Med Central and every scientist can read your work free of charge

"BioMed Central will be the most significant development for disseminating the results of biomedical research in our lifetime. " Sir Paul Nurse, Cancer Research UK

Your research papers will be:

- available free of charge to the entire biomedical community

- peer reviewed and published immediately upon acceptance

- cited in PubMed and archived on PubMed Central

- yours - you keep the copyright

Submit your manuscript here:

http://www.biomedcentral.com/info/publishing_adv.asp
BiolMedcentral 